\title{
Use of High-Frequency Jet Ventilation in the Management of Congenital Tracheoesophageal Fistula Associated With Respiratory Distress Syndrome
}

\author{
By Steven M. Donn, Linda K. Zak, Mary Ellen A. Bozynski, Arnold G. Coran, and Keith T. Oldham \\ Ann Arbor, Michigan
}

\begin{abstract}
- Two preterm infants (28 weeks, $960 \mathrm{~g}$ : 32 weeks, $1,870 \mathrm{~g}$ ) with very large tracheoesophageal fistulas suffered from respiratory distress syndrome and failed to respond to conventional mechanical ventilation despite placement of a decompressive gastrostomy. Pulmonary air leaks developed in both, resulting in transdiaphragmatic pneumoperitoneum, and significant gas flow occurred through the gastrostomy tube despite placement under water-seal. High-frequency jet ventilation was instituted in each case and resulted in improved pulmonary gas exchange at lower mean airway pressures $(12.0$ to $6.7 \mathrm{~cm}$ $\mathrm{H}_{2} \mathrm{O} ; 11.0$ to $8.0 \mathrm{~cm} \mathrm{H}_{2} \mathrm{O}$ ) and in prompt resolution of air leaks. Both patients remained refractory to reinstitution of conventional ventilation until division of the fistula in the first patient and complete resolution of the respiratory distress syndrome in the second.

(c) 1990 by W.B. Saunders Company.
\end{abstract}

INDEX WORDS: Tracheoesophageal fistula; respiratory distress syndrome; high-frequency jet ventilation.

$\mathbf{R}$ ESPIRATORY distress syndrome is a pulmonary disorder of the preterm infant characterized by poor lung compliance and high resistance. When this problem exists concomitantly with tracheoesophageal fistula (TEF), respiratory management may be extremely difficult, as tracheal gas flow is diverted through the fistula, leading to alveolar hypoventilation. Because these infants are too sick or too small for immediate surgical repair, interim mechanical measures, such as placement of a gastrostomy tube to underwater seal or insertion of a Fogarty balloon catheter to occlude the fistula, have been suggested as aids for ventilatory management. ${ }^{1}$

We recently treated two preterm infants with TEF complicated by respiratory distress syndrome, using high-frequency jet ventilation when conventional mechanical ventilation failed to achieve adequate pulmonary gas exchange.

\section{CASE REPORTS}

\section{Case 1}

This patient was a $960-\mathrm{g}$ girl infant born to a 26 -year-old primigravida who underwent premature onset of labor at 28 weeks and had a spontaneous vaginal delivery. Esophageal atresia was suspected when an orogastric tube could not be passed, and was confirmed along with a distal TEF by a radiographic contrast study. Shortly after transfer severe abdominal distention was noted (Fig 1) and abdominal paracentesis yielded air. An emergent laparotomy was performed and a gastrostomy tube was placed, along with three peritoneal drains. The pneumoperitoneum appeared to result from a transmediastinal air leak. She developed severe respiratory distress syndrome with pulmonary interstitial emphysema and could not be effectively ventilated, even at a high inspiratory pressure and rate (mean airway pressurc, $12.0 \mathrm{~cm} \mathrm{H}_{2} \mathrm{O}$ ). Significant air flow through the gastrostomy tube, despite water-seal, was noted. At 8 hours of age she was placed on high-frequency jet ventilation and tolerated an immediate reduction in mean airway pressure to $6.7 \mathrm{~cm} \mathrm{H} \mathrm{H}_{2} \mathrm{O}$ with improved pulmonary gas exchange. Prompt resolution of air leaks followed (Fig 2). However, all attempts to switch to conventional ventilation were unsuccessful until division of the fistula at 2 months of age. She was discharged at 99 days of age.

\section{Case 2}

This patient, an 1,870-g boy, was delivered by emergency cesarean section for fetal distress following a 32-week gestation complicated by polyhydramnios. Progressive respiratory distress necessitated intubation. Chest radiographs showed respiratory distress syndrome as well as esophageal atresia and TEF. An imperforate anus was noted on physical examination. Despite placement of a gastrostomy tube (and diverting loop transverse colostomy), his ventilatory support remained difficult. Significant air flow through the gastrostomy was observed, even with placement to underwater seal. He was placed on high-frequency jet ventilation at 20 hours of age after development of a pneumoperitoneum secondary to a transdiaphragmatic air leak. Mean airway pressure was decreased from $11.0 \mathrm{~cm}$ $\mathrm{H}_{2} \mathrm{O}$ to $8.0 \mathrm{~cm} \mathrm{H}_{2} \mathrm{O}$, air leaks resolved rapidly, and arterial blood gases improved dramatically. He was weaned slowly from highfrequency to conventional ventilation, which he tolerated, but only after resolution of his respiratory distress syndrome. He successfully underwent delayed primary repair at 12 days of age.

\section{DISCUSSION}

High-frequency jet ventilation is a recent ventilatory technique that uses extremely small tidal volumes at very rapid rates. It has been shown to allow adequate pulmonary gas exchange at significantly lower mean airway pressures and at extremely short inspiratory times. ${ }^{2}$ Previous studies have demonstrated the successful resolution of pneumothorax and pulmonary interstitial emphysema in infants with respiratory distress syndrome when high-frequency jet ventilation was used. $^{2-4}$

From the Section of Newborn Services, Department of Pediatrics, and the Division of Pediatric Surgery, Department of Surgery, University of Michigan, Ann Arbor, MI.

Presented in part at the 5th Conference on High-Frequency Ventilation of Infants, Snowbird, UT, April 8, 1988.

Address requests to Steven M. Donn, MD, L3023 Women's Hospital/0254, Ann Arbor, MI 48109-0254.

(c) 1990 by W.B. Saunders Company.

0022-3468/90/2512-0004803.00/0 


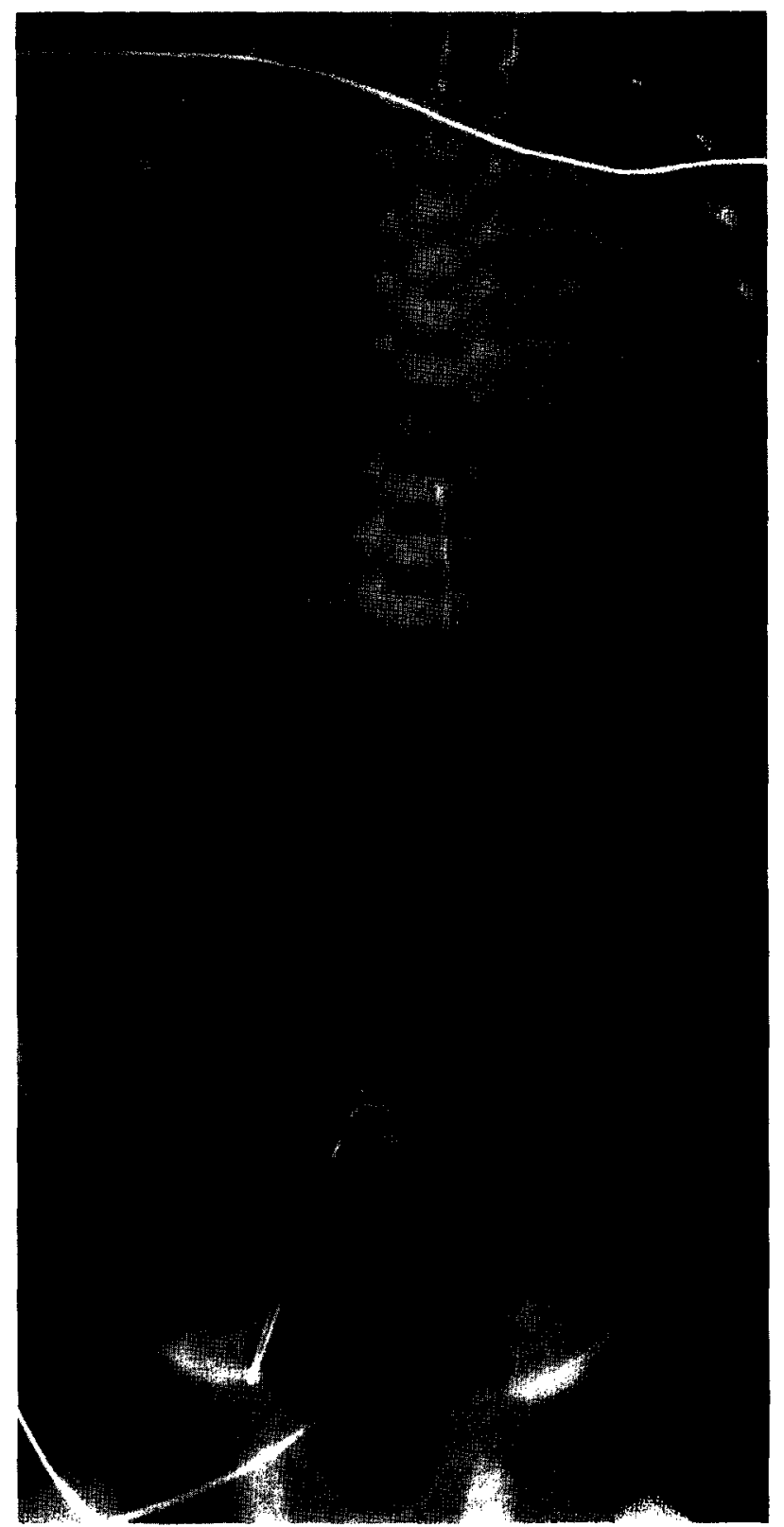

Fig 1. Case 1. Anteroposterior chest-abdomen radiograph demonstrating massive tension pneumoperitoneum, despite peritoneal drain.

The two cases presented also suggest a situation in which another unusual source of air leak, TEF, may be more amenable to high-frequency ventilation than conventional mechanical ventilation. In both instances high ventilatory pressures in the face of altered pulmonary compliance resulted in a situation where barotrauma produced additional air leaks (pulmonary interstitial emphysema, pneumoperitoneum). Moreover, delivered tidal gas took the path of least resistance, moving from trachea to esophagus. Prior to surgical division of the fistula in case 1 and complete resolution of the respiratory distress syndrome in case

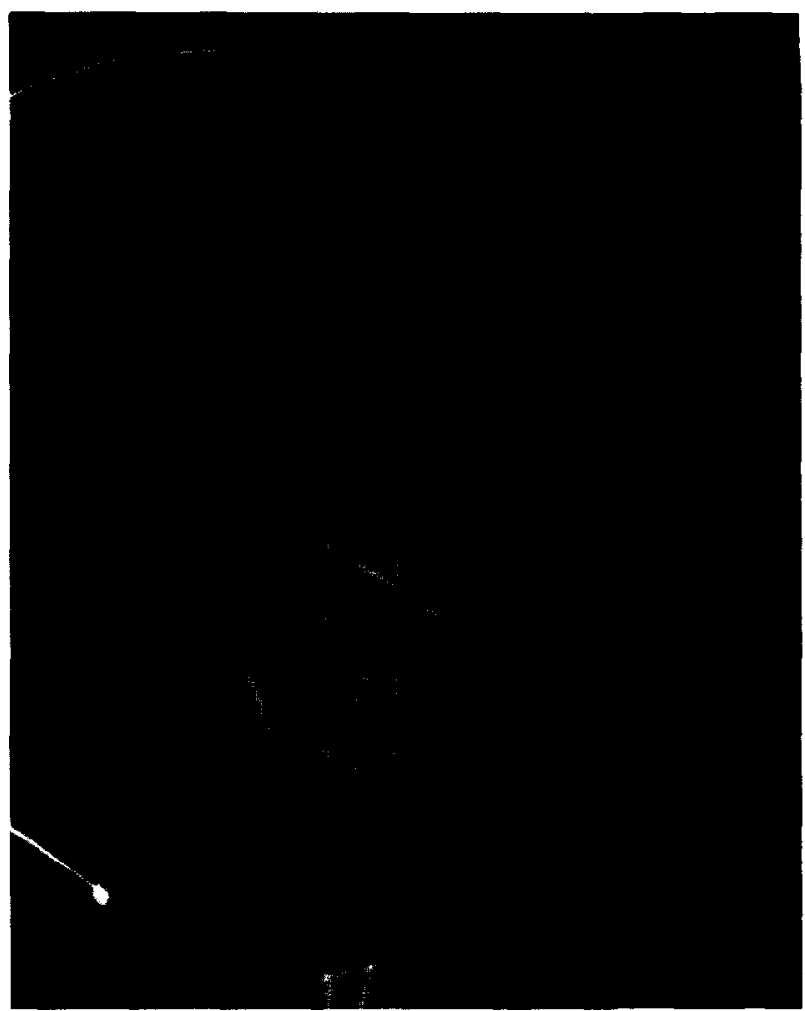

Fig 2. Case 1. Anteroposterior chest radiograph domonstrating resolution of tension pneumoperitoneum and establishment of apparently normal lung volumes ofter institution of high-frequency jet ventilation.

2 , all attempts to use conventional ventilation were unsuccessful.

Another possible mechanism to explain the success of high-frequency jet ventilation in these two patients is the wave form generated during jet ventilation. Jet

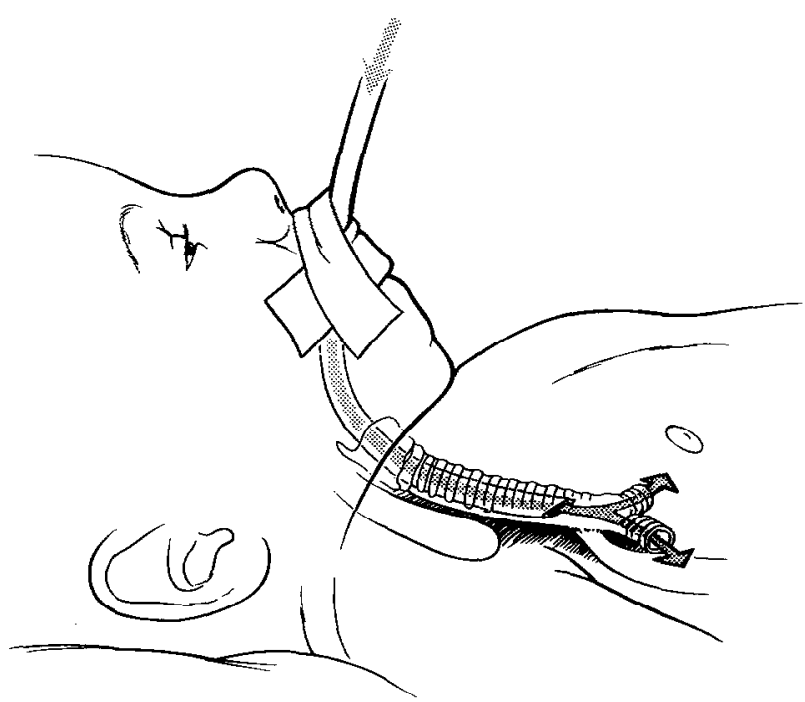

Fig 3. Schematic diagram indicating possible mechanism of high velocity laminar flow during jot ventilation that bypasses TEF. 
pulsations produce a higher velocity, more laminar gas profile than conventional mechanical breaths. This may enable the delivered gas volume to more effectively bypass the fistula (Fig 3).
Preterm infants with TEF complicated by respiratory distress syndrome should be considered candidates for high-frequency jet ventilation if conventional ventilation fails to achieve adequate pulmonary function.

\section{REFERENCES}

1. Filston HC, Chitwood WR Jr, Schkolne B, et al: The Fogarty balloon catheter as an aid to management of the infant with esophageal atresia and tracheo-esophageal fistula complicated by severe respiratory distress syndrome or pneumonia. J Pediatr Surg 17:149-151, 1982

2. Donn SM, Nicks JJ, Bandy KP, et al: Proximal high-frequency jet ventilation of the newborn. Pediatr Pulmonol 1:267-271, 1985

3. Pokora T, Bing D, Mammel M, et al: Neonatal high-frequency jet ventilation. Pediatrics 72:27-32, 1983

4. Carlo W, Chatburn RL, Martin RJ, et al: Decrease in airway pressure during high-frequency jet ventilation in infants with respiratory distress syndrome. J Pediatr 104:101-107, 1984 